\title{
Decision trees for implementing Rapid Manufacturing for Mass Customisation
}

\author{
Dominik Deradjat* and Tim Minshall \\ Institute for Manufacturing, University of Cambridge Department of Engineering, 17, Charles Babbage \\ Road, Cambridge CB3 OFS, UK \\ *Corresponding author: dominik.deradjat@gmail.com
}

\begin{abstract}
This paper aims to (1) compare implementation considerations and challenges for metal and polymer rapid manufacturing (i.e. the use of additive manufacturing technologies for final part production) for mass customisation and (2) derive decision trees for firms seeking to implement such an approach. Implementation data from 10 case studies from the dental and hearing aid industries has been captured and used as the basis for the comparison and design of the decision trees. Our objective is to provide evidence on the use of additive manufacturing technologies as enablers for mass customisation and to provide practitioners in industry with guidelines for decision-making on how to install and ramp-up mass customisation production with these technologies. Common considerations and challenges for both metal and polymer applications have been identified. Based on these insights, eight implementation decision trees have been created and represent the main contribution of this paper.
\end{abstract}

\section{Keywords}

Additive Manufacturing, Rapid Manufacturing, Mass Customisation, Ramp-up Management, Advanced Manufacturing Implementation

\section{Acknowledgements}

The research presented in this paper was supported by funding from the R\&D Management Association, the UK Engineering and Physical Sciences Research Council and the UK Economic and Social Research Council (EP/K039598/1). 


\section{Introduction}

Mass customisation ( $\mathrm{MC}$ ) - i.e. the production of individualised objects at mass production levels - can be realised through recent advances in the performance of additive manufacturing (AM) technologies (Deradjat and Minshall, 2017; Fogliatto et al., 2012). These advances enable the direct production of objects using $A M$, and this application of $A M$ is known as 'rapid manufacturing' (RM). The reason why $R M$ is said to enable $M C$ stems from the inherent advantages offered by $\mathrm{AM}$ technologies such as superiority in customisation and production flexibility (Weller et al., 2015). However, to date there have been very few successful applications of RM for MC (Fogliatto et al., 2012; Mellor et al., 2014; Sandström, 2015) and as a result, knowledge of the implementation process of successful RM systems that realise MC has not been widely diffused. In particular, the production ramp-up stage comprising the time between R\&D and fully working mass production is an area that has not been well researched.

There are three types of challenges that companies encounter when seeking to apply RM as a production process (Ruffo et al., 2007):

1. Manufacturing processes and materials

2. Design

3. Management, organisation and implementation

This paper targets the third category with an emphasis on implementation.

There are several industries applying RM (Wohlers and Caffrey, 2016) but very few are using it for mass customisation. 'True' mass customisation (MC) has to fulfil the requirement of providing highly individualised products at high output numbers (Piller, 2008). Two most successful areas have been dental and hearing aid applications (Deradjat and Minshall, 2015; Mellor, 2014). Building on the work of Deradjat and Minshall (2017) that focused specifically on metal RM implementation for MC in the dental industry, this paper seeks to develop more generalised and detailed instructions on how to implement RM for MC. In addition, in order to cover the most relevant $\mathrm{AM}$ process for $\mathrm{MC}$, comparable insights for polymer RM cases for $\mathrm{MC}$ need to be established. One of the most promising applications for this type of AM is the hearing aid industry as indicated by Sandström (2015). The hearing aid industry provides an appropriate number of companies that have successfully implemented RM for MC to warrant an in-depth analysis similar to the one carried out by Deradjat and Minshall (2017).

Our research targets gaps in literature on $\mathrm{MC}$ enablers by providing an understanding of how enterprises implement metal and polymer RM for MC. There is a distinct lack of research in literature regarding in-depth implementation instructions of how to implement the discussed principles. In addition, the paper provides detailed instructions for decision makers on how to implement RM for MC in the form of decision trees. Within this context, the following research question and sub-question has been formulated: 
- Research question: Which aspects do companies seeking to implement RM for MC have to consider in their decision-making process?

- Research sub-question: Which common considerations and challenges ${ }^{1}$ exist during the implementation process of RM for MC for metal and polymer RM?

In the following section, a review of literature on $\mathrm{MC}$ and $\mathrm{RM}$ is presented. The subsequent section presents the research methodology and contextual information regarding the polymer RM for MC cases. Next, the research results from the hearing aid industry cases are presented and contrasted against the results obtained from Deradjat and Minshall (2017). The results will be presented according to the framework categories of strategic, technical, operational, organisational and external considerations. Based on these insights a decision tree will be derived for each of the stated categories. The paper closes with the conclusions, limitations of the research and suggestions for further research.

\footnotetext{
${ }^{1}$ The paper will merge 'considerations and challenges' since 'considerations' can represent challenges and vice versa.
} 


\section{Literature review}

\subsection{Additive Manufacturing technologies and Rapid Manufacturing}

Rapid Manufacturing describes the use of Additive Manufacturing technologies for the production of final parts. According to Hopkinson et al. (2006, p.1), it is defined as:

"the use of a computer aided design (CAD)-based automated Additive Manufacturing process to construct parts that are used directly as finished products or components".

Additive Manufacturing (AM) is defined as:

"the process of joining materials to make objects from 3D model data, usually layer upon layer, as opposed to subtractive manufacturing methodologies" (ASTM, 2012, p. 2).

Wong and Hernandez (2012) classify AM according to the method of material supply into liquid based, solid based and powder based systems (See Figure 1). Processes utilised in our case studies are Selective Laser Sintering (SLS), Selective Laser Melting (SLM) and Direct Metal Laser Sintering (DMLS) for metal parts and Stereolithography (SLA) and Digital Light Processing (DLP) for polymers.

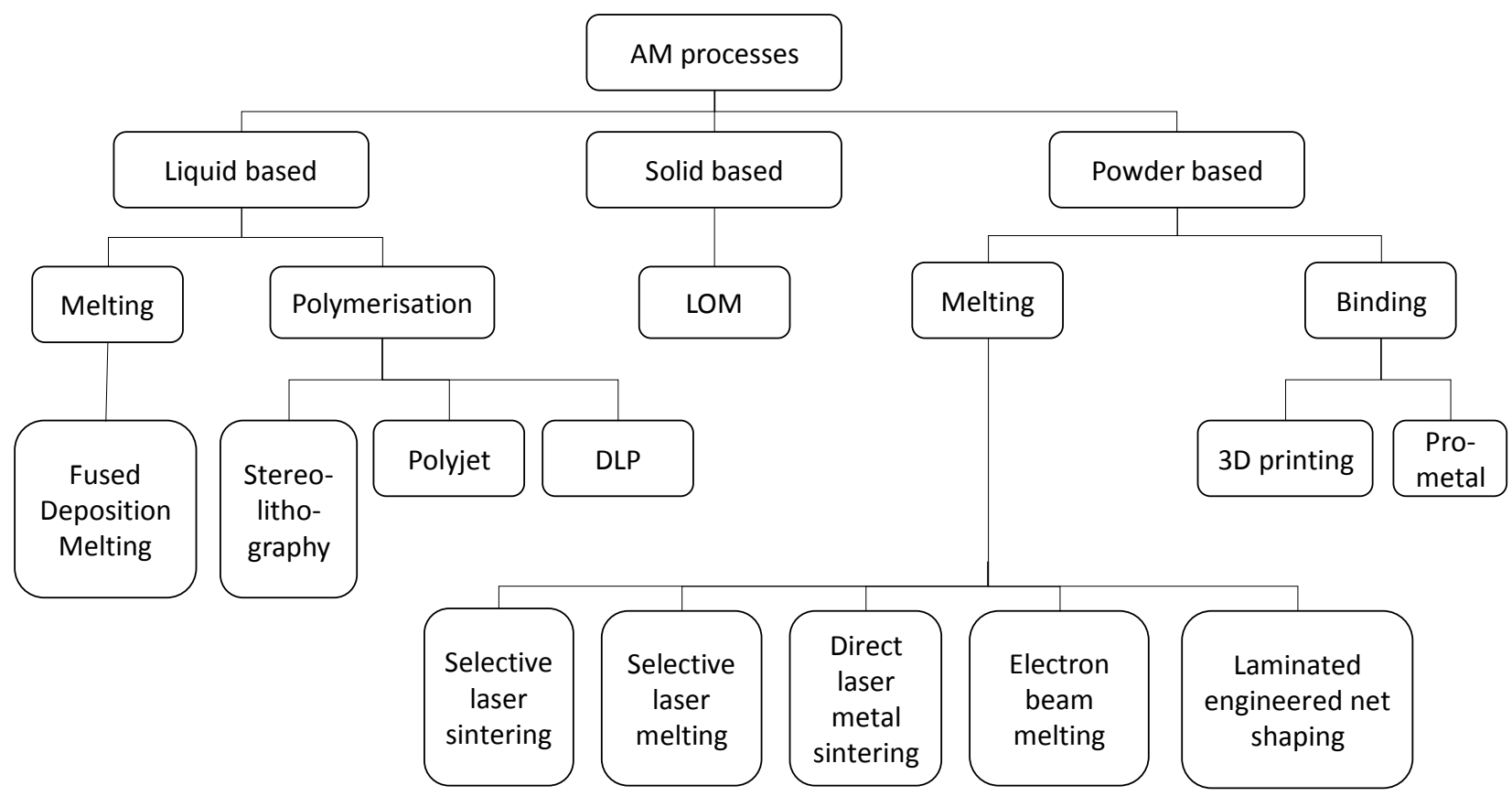

Figure 1: Classification of additive manufacturing technologies based on Wong and Hernandez (2012)

RM evolved from Rapid Prototyping, which describes the creation of prototypes through AM. Rapid Prototyping was first deployed in the 1990s (Atzeni et al., 2010). Over time AM technologies have evolved to realise the production of moulds and tooling inserts (Pham and Dimov, 2001). Increased investment in R\&D for AM technologies over the past 10 years have resulted in improvements in the performance of AM such that it has become capable for final part production (RM) in certain applications (Mellor et al., 2014). Utilising AM for direct production has several advantages compared to traditional manufacturing technologies (Holmström et al., 2010):

1. Absence of tooling requirements reduces production time and expenses 
2. Small production batches become feasible and economical

3. Quick design changes are possible

4. Production can be optimised in regard to functional purposes

5. Custom products become economically viable

6. Waste is reduced

7. Supply chains can be simplified

8. Design of products can be customised

In particular, the benefit of design customisability has been said to realise the production strategy of Mass Customisation (MC) (Fogliatto et al., 2012). However, the literature on RM for MC (such as the work by Reeves et al. (2011) and Gibson et al. (2010)) either merely describe potential applications or enumerate existing applications without providing in depths technical and industrial insights. Only Deradjat and Minshall (2017) provide a framework of RM for MC implementation derived from in-depth industrial insights and research by Mellor et al. (2014). However, Deradjat and Minshall (2017) do not provide clear guidance on how companies should proceed when attempting to implement RM for MC. Their research is additionally limited to metal RM. Thus, there is a need to expand the work to include polymer AM technologies in order to develop a broader understanding of how RM can be implemented. While insights on the industrial adoption of polymer RM has been carried out by Sandström (2015), his research takes a more industry centric view and does not provide sufficient data to capture technical implementation aspects. In light of the foundational work on the implementation of RM for MC provided by Deradjat and Minshall (2017), there is a need to supplement the data base for polymer RM and to further develop these insights to provide more advanced implementation instructions that can benefit both literature and practitioners seeking to implement RM for MC.

\subsection{Mass Customisation}

"Mass customisation" is a term introduced by Davis (1987) and Pine (1993) to describe the production strategy of realising the manufacture of customised objects at mass production level. The concept is based on Hayes and Wheelwright's (1979) product process matrix (Duray, 2011). MC represents a hybrid version of one-off and mass production. Within the product process matrix illustrated in Figure 2, MC is located between individual production in the top left-hand corner and mass production in the lower right-hand corner (Tuck et al., 2008). 


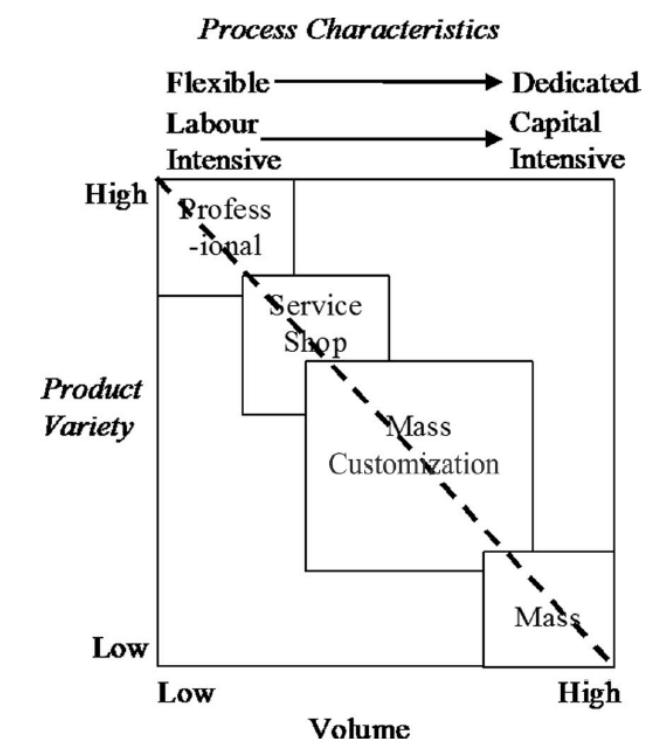

Figure 2: Product variety-volume matrix (Tuck et al., 2008)

'Customisation' denotes the input of the customer during the design process (Lampel and Mintzberg, 1996). According to Lampel and Mintzberg (1996), there are varying degrees of customisation spanning from the highest degree of customisation, namely 'pure customisation', and 'standardised customisation'. In literature there is no prescribed level of customisation and production volume that defines MC (Bateman and Cheng, 2006). Some scholars believe that MC only exists if the customer is able to completely customise the product in every aspect (Silveira et al., 2001). Others such as Westbrook and Williamson (1993) accept limited customer involvement and influence on the product design to qualify as MC. Equally, there is no agreement on the required level of production output that qualifies for MC. Instead, Duray et al. (2000) state that in an optimal case of MC production efficiency of $\mathrm{MC}$ should be close to those of mass production.

Fogliatto et al. (2012) conducted a review of MC literature and have categorised it into (i) the economics of the principle, (ii) success factors, (iii) $M C$ enablers and (iv) customer-manufacturer interaction. Considering the above-mentioned advantages of $A M$, this research focuses on the body of literature on MC enablers. A particular lack of research on implementation models of manufacturing technologies for MC enablers have been identified by Fogliatto et al. (2012) and Deradjat and Minshall (2017). Given the noted advances of RM within recent years, there is a need to study how AM technologies can help realise MC. Weller et al. (2015) support this endeavour by suggesting that AM allows an enterprise to increase profits by capturing value through flexible production of customised objects. Deradjat \& Minshall (2017) propose a framework for implementation of RM for MC taking into account strategic, technological, operational, organisational and external considerations (Figure 3). While their research outputs present a conceptual framework and a list of relevant challenges, a detailed contribution on how to proceed with the implementation process of RM for MC is absent in literature. 


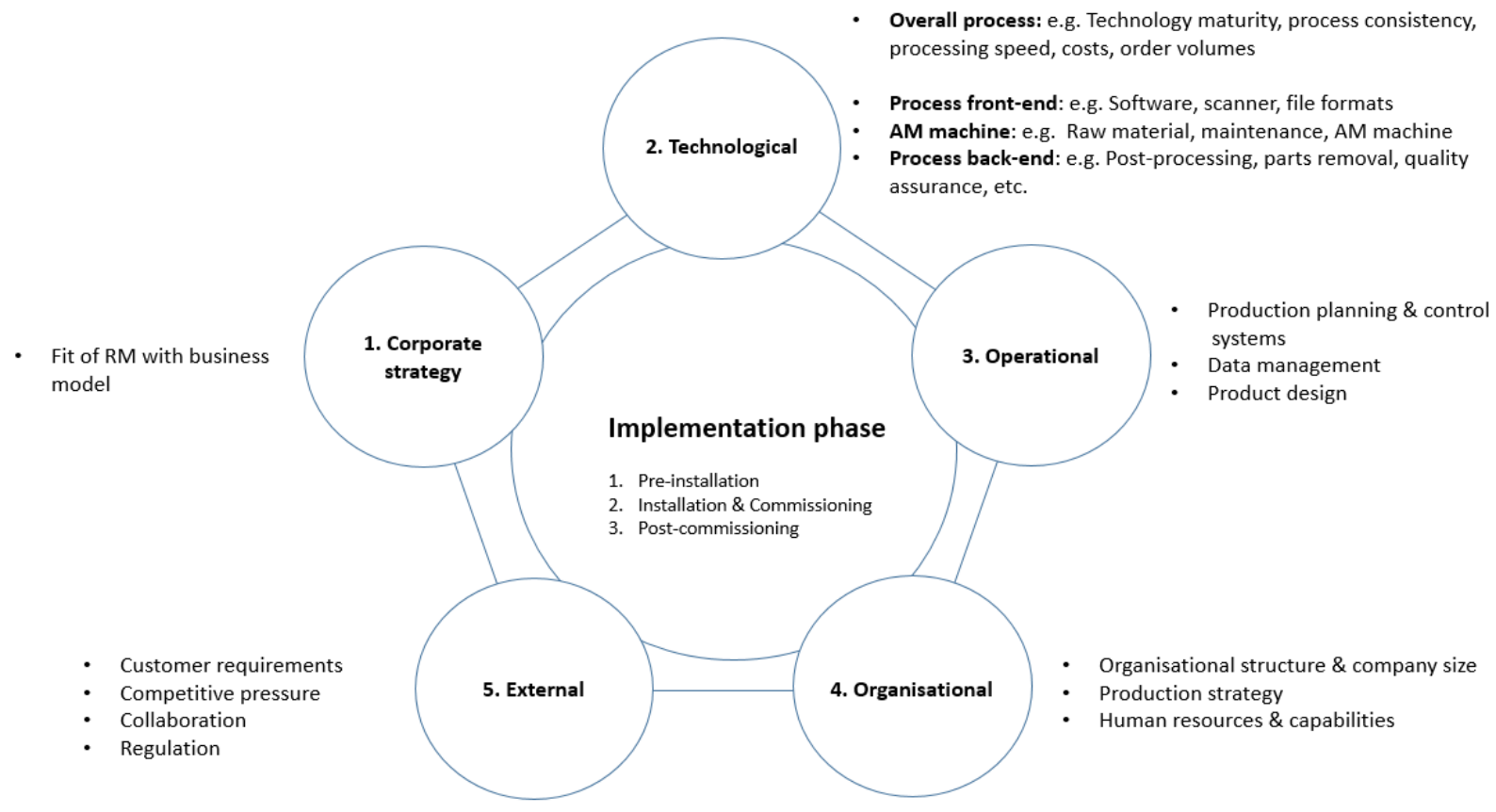

Figure 3: Framework of Rapid Manufacturing implementation for Mass Customisation (Deradjat and Minshall, 2017)

In this paper, $M C$ is defined as a production strategy which relates to the manufacture of individualised and unique objects at output levels characteristic of mass production. Each product is different from another in shape and size.

Our review has revealed that with the benefits and advances of AM technology, RM can become an enabler for MC. While there is research on RM and MC, there is a lack of research where and how these two fields intersect. This paper seeks to build on the foundations provided by Deradjat and Minshall (2017) and extend them to create detailed instructions of how RM for MC can be realised. This research will supplement existing research for metal RM for MC with four cases for polymer RM and derive decision trees for RM implementation of MC. The concept of implementation has been defined by Voss (1988) along a three stage life-cycle model (Figure 4).

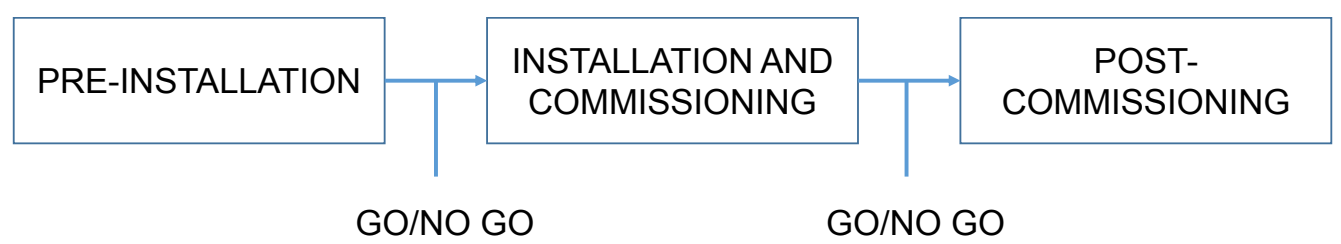

Figure 4: Implementation process according to Voss (1988)

The first 'pre-installation' phase comprises all variables pertaining to the success or failure of the implementation process. In the second phase, the installation and commissioning phase, a working order of the applied technology on a consistent level is guaranteed. The last step, the post-commissioning phase, consists of improvement of technical and business operations. According to Voss (1988), this final phase should never end since an effective company should seek to continuously improve. In the context of this paper, the definition of implementation stated by Voss (1988) will be adopted. 


\section{Research methodology}

The research is divided into two parts. Firstly, an in-depth analysis of the hearing aid industry was conducted in an identical manner as carried out by Deradjat \& Minshall (2017). The results are summarised in a table at the beginning of each sub-chapter in section 4 (e.g. Figure 6Figure 6) together with the relevant insights from Deradjat \& Minshall (2017). This serves the purpose of enhancing understanding of RM for $\mathrm{MC}$ to include polymer RM applications allowing for more generalised conclusions. A within-case analysis and a subsequent cross-case analysis identified challenges that were reoccurring among the majority of the polymer RM cases.

Secondly, the research results for metal and polymer RM are compared and provide the basis for the formulation of decision trees for the implementation of RM for MC. These decision trees are derived primarily from the data provided in our cases, i.e. from interviews, production data and literature. While polymer case insights are derived from primary case data (e.g. interviews, production data of the companies), metal case references in this paper are taken from Deradjat \& Minshall (2017). The decision trees represent the challenges and insights that companies in the stated case studies were facing.

To account for the novelty and exploratory nature of our research objective, a case study based research design is most appropriate. A multi-case design has been chosen to enable inter case comparison and robustness and generalisability of the findings (Herriott and Firestone, 1983). Since the paper seeks to analyse several aspects in order to capture a comprehensive picture of implementation of RM for MC, multiple units of analysis are required with an embedded multi-case study design according to Yin (2009). Four companies from the hearing aid industry are analysed. The framework provided by Deradjat \& Minshall (2017) will serve the purpose of providing a structure for the data gathering phase and for deriving decision trees for the implementation of RM for MC. The framework categories comprise corporate strategy, technical (overall RM process, process front-end, AM machine, process back-end), operational, organisational and external considerations. In order to ensure comparability of results between this research and the insights from the hearing aid industry and the dental industry from Deradjat \& Minshall (2017), the same data acquisition methodology was used.

A wide range of data sources have been utilised. In each case, production data and publicly available financial data from annual reports and government databases have been processed, supplemented with interviews with company representatives who are familiar with the RM implementation process. Additionally, to increase validity of the cases, data from AM machine and software providers have been included. Table 1 gives an overview of the case companies. 
Table 1: Information on hearing aid case companies

\begin{tabular}{|c|c|c|c|c|c|c|}
\hline Company & AM Products & $\begin{array}{l}\text { Number of units } \\
\text { produced per } \\
\text { year }\end{array}$ & AM Process & $\begin{array}{l}\text { Size of } \\
\text { company }\end{array}$ & Other & Informant \\
\hline Company 1 & $\begin{array}{l}\text { Hearing aid } \\
\text { shells }\end{array}$ & $>1,000,000$ & SLA, DLP & $\begin{array}{l}\text { Germany based } \\
\text { multinational } \\
\text { company, } \\
>€ 835 \mathrm{~m} \\
\text { annual sales }\end{array}$ & $\begin{array}{l}\text { First company to } \\
\text { implement AM in the } \\
\text { hearing aid industry, } \\
\text { collaboration with } \\
\text { Company } 3 \text { during } \\
\text { pre-installation } \\
\text { phase }\end{array}$ & $\begin{array}{l}\text { Head of custom } \\
\text { hearing aid production }\end{array}$ \\
\hline Company 2 & $\begin{array}{l}\text { Hearing aid } \\
\text { shells }\end{array}$ & $>1,000,000$ & DLP & $\begin{array}{l}\text { US based } \\
\text { multinational } \\
\text { company, } \\
>\quad € 770 \quad \mathrm{~m} \\
\text { annual sales }\end{array}$ & $\begin{array}{l}\text { Late follower of AM } \\
\text { adoption }\end{array}$ & Head of production \\
\hline Company 3 & $\begin{array}{l}\text { Hearing aid } \\
\text { shells }\end{array}$ & $>1,000,000$ & DLP & $\begin{array}{l}\text { Switzerland } \\
\text { based } \\
\text { mulitinational } \\
\text { company, } \\
€ 2.23 \text { b annual } \\
\text { sales }\end{array}$ & $\begin{array}{l}\text { Collaboration with } \\
\text { Company } 1 \text { during } \\
\text { pre-installation } \\
\text { phase }\end{array}$ & $\begin{array}{l}\text { Director of custom } \\
\text { products }\end{array}$ \\
\hline Company 4 & $\begin{array}{l}\text { Hearing aid } \\
\text { shells }\end{array}$ & $>500,000$ & SLA & $\begin{array}{l}\text { US based } \\
\text { multinational } \\
\text { companv }\end{array}$ & Late follower & $\begin{array}{l}\text { Head of production } \\
\text { North America }\end{array}$ \\
\hline
\end{tabular}




\section{Results and discussion}

The challenges involved with the implementation of RM for MC gathered from Minshall \& Deradjat (2017) and four cases from the hearing aid industry are presented in this section. Based on these insights, decision-making trees of how to implement RM for the following five categories as identified by Mellor (2014) and Deradjat and Minshall (2017) are synthesised. Figure 5 illustrates the different categories of strategic, technological, operational, organisational and external and their contextual relation to each other.

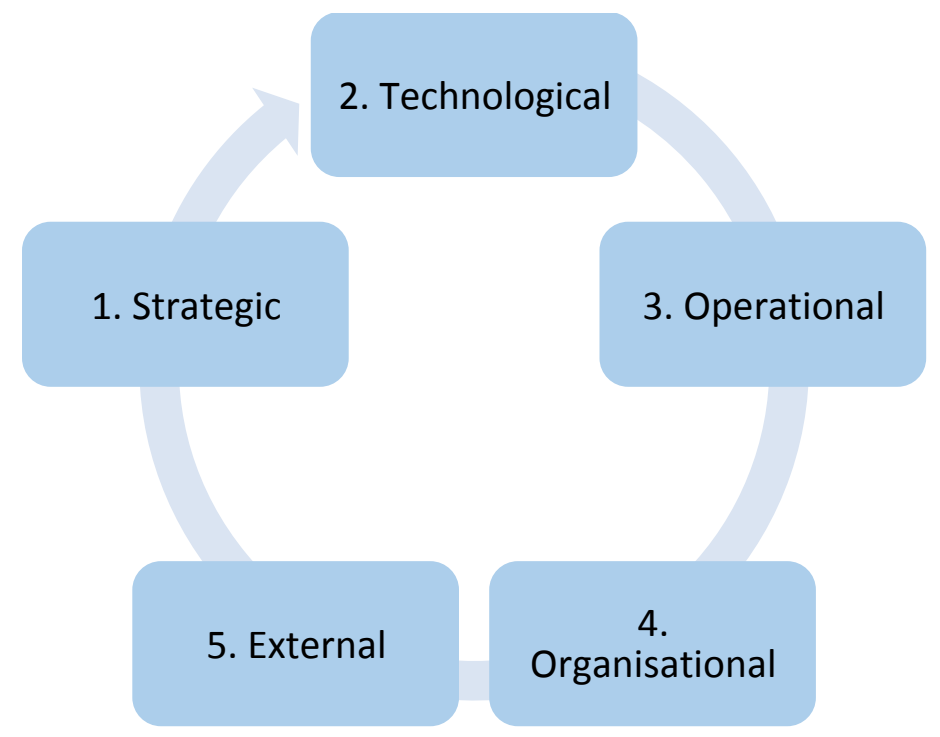

Figure 5: Overview decision-making categories

Each sub-section is structured to first answer the research sub-question and then contribute to the main research question. Each subsequent section starts with an identification of considerations that have been deemed relevant for each framework category. Each of these are then compared with each other for both metal and polymer RM for MC. Only considerations that have occurred in the majority of cases were captured in the following sections. This rational of data analysis corresponds to the logic of how data was captured by Deradjat \& Minshall (2017) for metal RM/dental cases. Such a uniform way of data analysis ensured comparability of results. Decision-making trees are then derived for each sub-section from the above-mentioned insights, thus directly addressing the main research question of which aspects companies have to consider in their decision-making process when implementing RM for MC.

Within our analyses and subsequent derivation of decision trees, each of the five framework factors will be divided according to the implementation phases suggested by Voss (1988). To reduce the complexity of presentation, the results for the pre-installation and installation phase have been merged since many considerations overlapped.

\subsection{Strategic considerations}

For corporate strategic considerations, both metal and polymer cases showed that RM generally offered a competitive advantage because of high process consistency and reduced scrap rate (Table 2). Ease of production scalability and cheaper production costs per unit produced were observed for the hearing aid cases but not for the dental refinement cases. For the dental industry, RM was primarily adopted because of the industry's trend towards digitised operations in dentistry. 
Table 2: Summary of strategic considerations and challenges

\begin{tabular}{|c|c|c|c|}
\hline Category & Considerations and challenges & $\begin{array}{l}\text { Hearing } \\
\text { Aid }\end{array}$ & Dental \\
\hline \multicolumn{4}{|l|}{ Corporate strategy } \\
\hline \multirow[t]{2}{*}{ All implementation phases } & - RM offered a competitive advantage because of high process consistency & $\mathrm{x}$ & $\mathrm{x}$ \\
\hline & $\begin{array}{l}\text { - RM was adopted in the context of an industry trend towards digital geometry } \\
\text { capture and production }\end{array}$ & & $\mathbf{x}$ \\
\hline
\end{tabular}

Figure 6 illustrates a decision tree for strategic considerations of RM for $\mathrm{MC}$ implementation. Actions and considerations are highlighted in light grey. It is crucial for companies seeking to implement RM for MC to first determine their key objectives and then to verify whether AM is in line with their business strategy and whether advantages of RM compared to the traditional process are compelling. Should these questions be negated, AM would not present a viable option. We found that all case companies had to go through these mentioned steps. In all cases, they found that AM was in line with their business strategy of moving towards digital dentistry or to aim for production ramp-up and business expansion as observed in the hearing aid cases. Additionally, RM for MC offered the advantage of high process consistency compared to traditional manufacturing processes (e.g. casting). The investigated cases show that these can comprise higher production scalability, better process consistency, better design freedom, better integration possibilities with digital production, cost advantages and superior production flexibility.

As a next step, companies have to decide whether they would like to be first to adopt RM for MC or whether they like to follow at a later point in time. For the later option, they have to execute a comprehensive technological assessment of available components and adopt the best possible RM systems on the market. If companies are the first to apply RM for MC in their respective field, they will have to determine whether they can cope financially with the high up-front costs and risk of failure. Should the costs and risks be acceptable, they will have to proceed to test whether technical, operational, organisational and external factors are favourable. Alternatively, collaborations can be of use if $R \& D$ costs cannot be covered internally. Here the company needs to carefully assess whether the risks are acceptable. Company 1 , for example, had to spend significant resources as the first company in the hearing aid industry to adopt AM for their particular application. However, smaller companies in the dental industry relied on collaborations to reduce risks and costs. In case of RM for MC implementation, the first-mover company can decide to keep the knowledge or IP internal and try to leverage AM as a competitive advantage as in the case of Siemens (Lieberman and Montgomery, 1988). A second option is to patent and license elements of the process, material, etc. This option allows income through royalty fees, awareness of the market and opportunities for collaboration with software companies, AMmachine and material providers. A third option is to file patents and not to license the IP in order to ensure a competitive advantage. This practice, however, has not been observed in any of the case companies. If the upfront R\&D costs are not affordable for an enterprise seeking to apply RM for MC first in their field, it needs to verify the feasibility of collaborations. Without collaborations, RM for MC implementation is not realisable at this stage. Should collaborative work be possible, an evaluation of the risks has to be executed. Data sensitivity and high failure potential can terminate further deliberation. If the risks are acceptable, the other implementation decision trees need to be checked as mentioned above. 


\section{Corporate strategy}

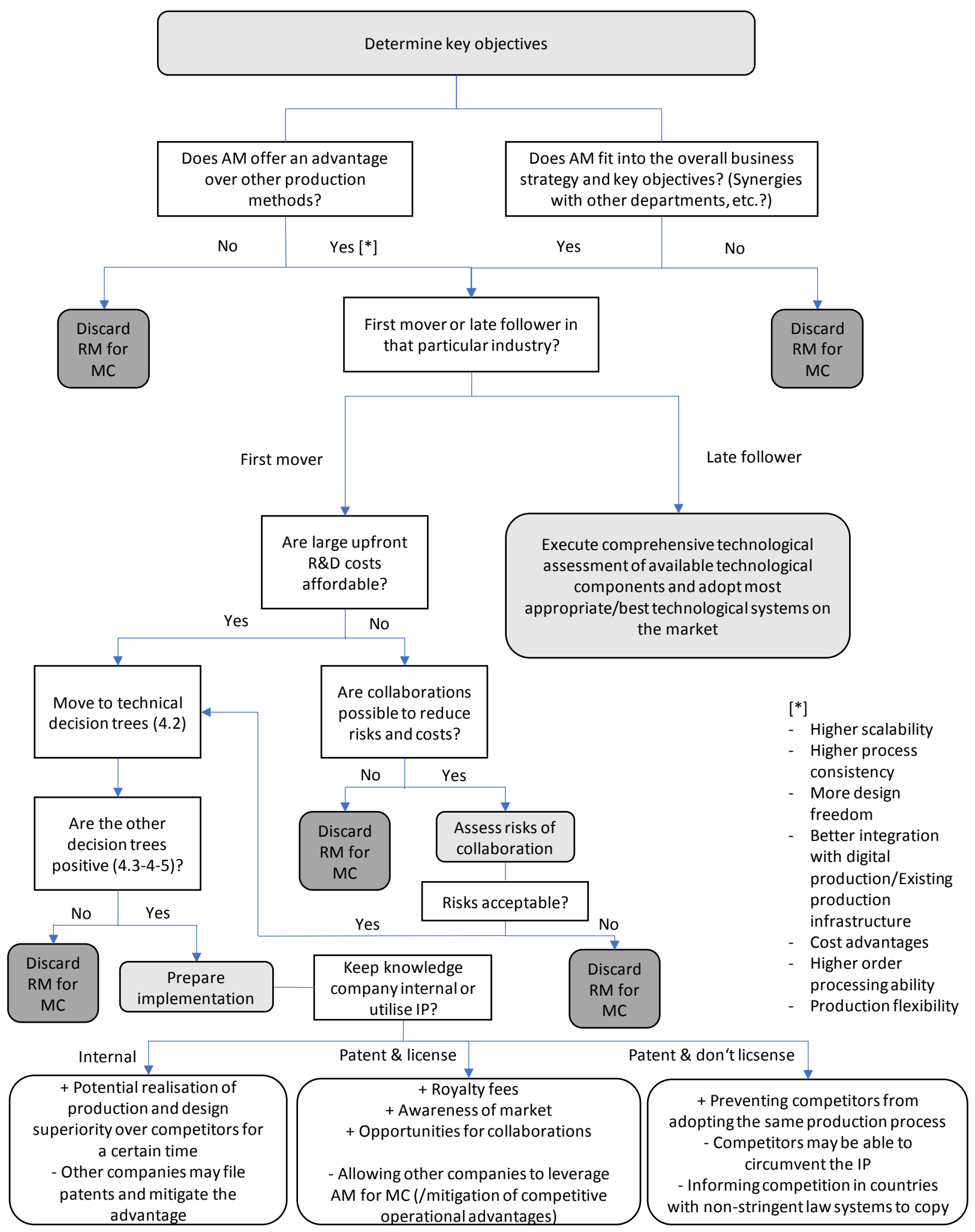

Figure 6: Strategic considerations. Decision tree for RM for MC implementation 


\subsection{Technological factors}

\subsubsection{Overall process}

For the technological overall process considerations, setting up a production planning system and product identification system was pivotal during the pre-installation and installation phase for cases from both industries (Table 3).

Table 3: Summary of overall process considerations and challenges

\begin{tabular}{|c|c|c|c|}
\hline Category & Considerations and challenges & $\begin{array}{l}\text { Hearing } \\
\text { Aid }\end{array}$ & Denta \\
\hline \multicolumn{4}{|l|}{ Technical (Overall process) } \\
\hline \multirow[t]{2}{*}{ Pre-installation, installation phase } & $\begin{array}{l}\text { - Setting up a production planning system and product identification system was } \\
\text { considered a challenge and crucial for the successful implementation of RM for MC }\end{array}$ & $\mathrm{x}$ & $\mathrm{x}$ \\
\hline & - Ensuring process consistency was a major challenge & $\mathbf{x}$ & $\mathbf{x}$ \\
\hline \multirow[t]{2}{*}{ All implementation phases } & - Product handling after AM process was a challenge as parts are still in a green state & $\mathbf{x}$ & \\
\hline & - Cost distribution: Front-end, machine related, back-end: $50 \%, 25 \%, 25 \%$ & $\mathbf{x}$ & \\
\hline
\end{tabular}

The topic of process consistency in the context of RM for MC was crucial for all case companies. Most case companies spent significant resources on ensuring that the process is consistent. This includes adaptations of front-end, AM machines, post-processing and operational factors. The example of Company 4 which already had a consistent RM (SLA) for MC production system in place and which refused to switch to a cheaper and more accurate AM process (DLP) illustrates the high level of resource input required to establish a consistent RM for $\mathrm{MC}$ process. Considering the importance of process consistency for the success of RM for MC implementation, companies seeking to implement RM for MC in other industries, will have to spend a significant amount of resources to ensure process consistency and product traceability: More specifically, this entails the successful synchronisation of front-end, AM machine and back-end factors. The scope of resources to be spent on this endeavour depends heavily on the technology maturity of each of these components as observed in the case studies. Figure 7 depicts the decisions and actions that have to be taken into account regarding the overall process when implementing RM for MC. In the pre-installation and installation phase, it is crucial to determine how much adaptation each technological component requires. In most cases, especially when technologies were not mature enough for an application, attaining process consistency required collaboration with external parties. Costs of operating RM for MC varies depending on the AM process used and the level of design that a company executes. For polymer processes, all cases show a cost distribution of $50 \%, 25 \%$ and $25 \%$ respectively for front-end, AM machine related and back-end factors in all implementation phases. For metal AM, this distribution is higher for back-end factors with $35-40 \%$ and significantly lower for front-end ones. Companies seeking to implement polymer AM have to be aware that product handling can present a challenge during all implementation stages since the part leaves the AM machine in a 'green' state, a state in which parts require further treatment in order to gain their intended material properties (e.g. to lower porosity). 


\section{$\underline{\text { Technological - Overall process }}$}

Determine if RM for $\mathrm{MC}$ needs to be adapted for the respective application and whether all components are commercially available

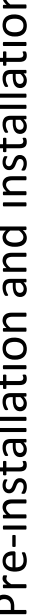

Does RM for MC have to be adapted?

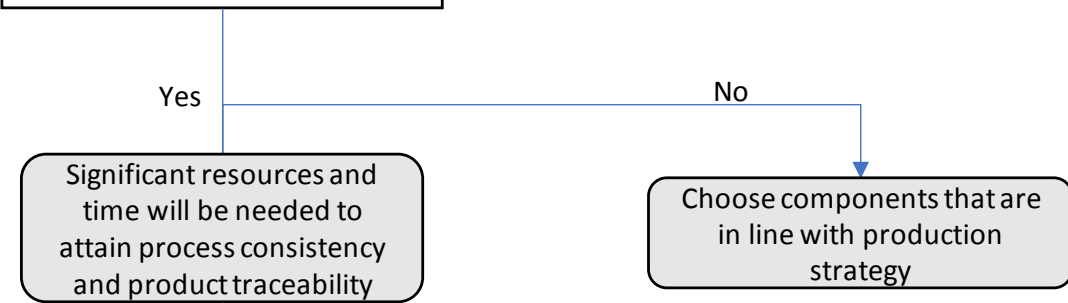

Type of AM process and degree of design?

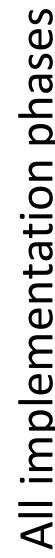

Polymer, high degree of design

Costs: Front end: $50 \%, \mathrm{AM}$ machin: 25\% Back-end: 25\%

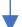

Product handling in green state can present a

challenge (name AM processes)
Metal, low degree of design

Costs: Back-end: $35-40 \%$

Figure 7: Technological overall process considerations. Decision tree for RM for MC implementation

\subsubsection{Front-end}

For front-end considerations, both companies in the hearing aid sector and the dental sector had to collaborate with software providers or machine producers to develop software during the preinstallation phase and installation phase (Table 4). 3Shape software reduced file preparation steps from the pre-installation and installation phase to the post-commissioning phase. Scanning of an imprint or intra-oral scan provided a possibility for geometrical error in the RM produced part (as well as increased the tolerance stack-up) in all implementation phases. 
Table 4: Summary of technological front-end considerations and challenges

\begin{tabular}{|c|c|c|c|}
\hline Category & Considerations and challenges & $\begin{array}{l}\text { Hearing } \\
\text { Aid }\end{array}$ & Denta \\
\hline \multicolumn{4}{|l|}{ Technical (Front-end) } \\
\hline \multirow[t]{2}{*}{ Pre-installation, installation phase } & $\begin{array}{l}\text { - Co-development of software and collaboration with software providers and machine } \\
\text { manufacturers was necessary }\end{array}$ & $\mathrm{x}$ & $\mathrm{x}$ \\
\hline & - Software required high labour input & $\mathbf{x}$ & $\mathbf{x}$ \\
\hline Post-commissioning phase & $\begin{array}{l}\text { - Software required less labour input than in the pre-installation and installation } \\
\text { phase due to automated file design features offered by } 3 \text { Shape but full automation } \\
\text { was not possible }\end{array}$ & $x$ & $x$ \\
\hline All implementation phases & $\begin{array}{l}\text { - Scan accuracy could vary leading to inaccurices in the produced part (esp. with } \\
\text { tolerance stack-up) }\end{array}$ & $\mathbf{x}$ & $\mathbf{x}$ \\
\hline
\end{tabular}

It is important to also note that the more front-end activities a company decided to incorporate in their business model, the more difficult RM implementation for MC became. This observation can be clearly made when contrasting hearing aid companies which executed the entire file design and the dental companies, which did not execute any extensive file design operations. As there is currently no software that allows to fully automate file design, scalability of RM for MC is highly dependent on human labour for companies choosing to offer file design services. From these observations, it becomes apparent that during the pre-installation and installation phase companies seeking to implement RM for MC need to first ascertain which front-end processes are to be executed in-house and whether the necessary frontend components such as scanners and software are available. Figure 8 illustrates a decision tree based on these identified challenges and insights derived from the 10 case studies. Should the components not be available, the company seeking implementation can either develop these in-house if it makes economic sense or enter a collaboration with external parties to develop these. If the components are available, however, the next step will be to assess to what degree automation of front-end processes can be realised. In case that automation can be realised, an analysis of the process steps and the number of steps that can be automated needs to be ascertained. With a low degree of automation with existing front-end technologies, collaborations and development with software companies can potentially increase automation. Should the analysis yield a high level of attainable automation, only the appropriate front-end technology remains to be chosen. If, however, front-end processes are generally not automatable, outsourcing to lower wage countries could enhance economic viability of an RM for MC concept. Weighing the cost of these outsourced front-end services is crucial. During all implementation phases, it is important to account for and control the tolerance stack-up that may occur if scanning is involved. In many medical applications scanning of a body part or scanning of an imprint and subsequent data manipulation may lead to an accumulation of geometrical errors. 


\section{$\underline{\text { Technological - Front-end }}$}

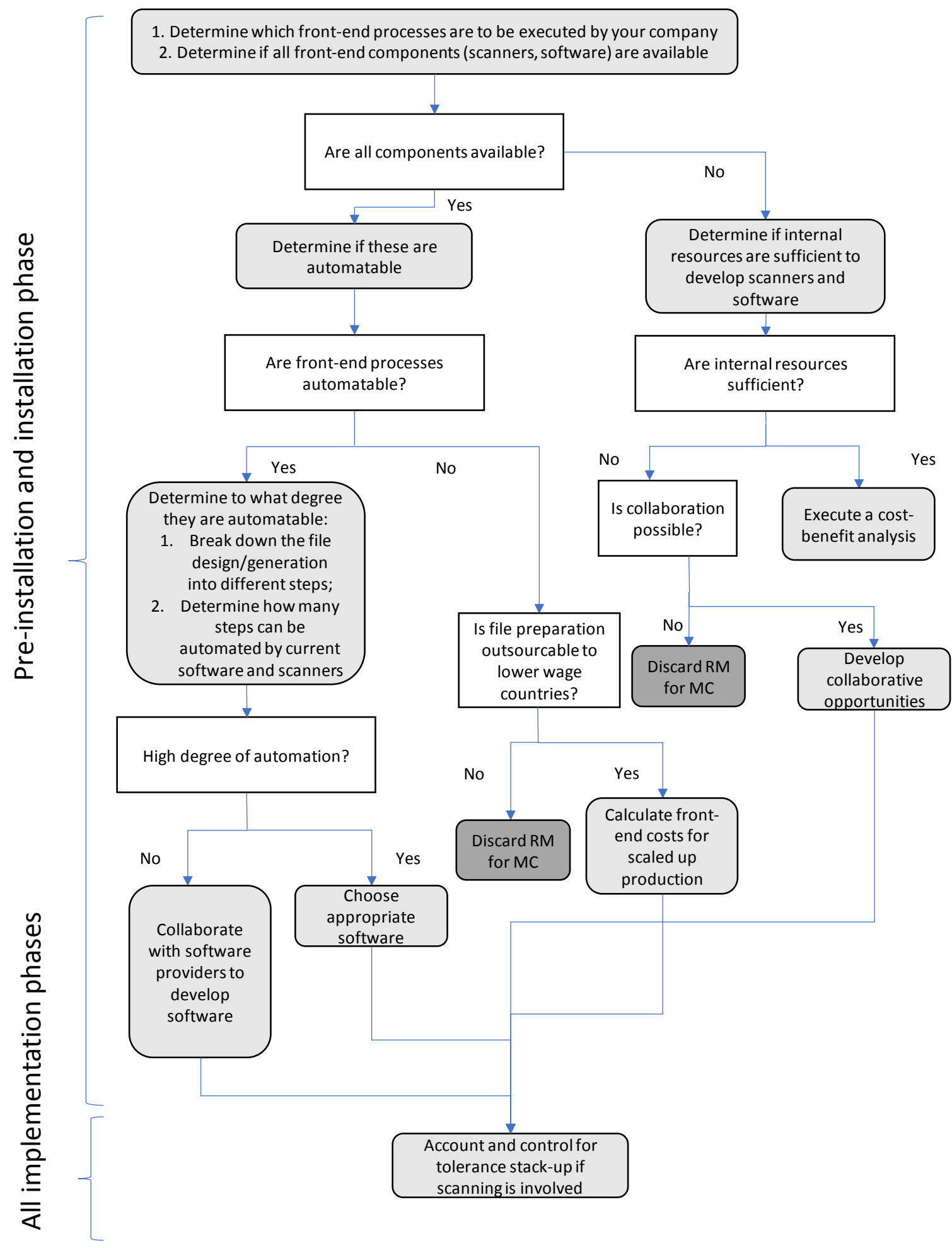

Figure 8: Technological front-end considerations. Decision tree for RM for MC implementation 


\subsubsection{Additive manufacturing equipment}

AM machine related factors comprise the fact that all AM machines, both metal and polymer, have to be adapted to specific applications in regard to process parameter. This can also correlate with adaptations and development of raw material, which in our focus industries need to be biocompatible. Metal RM or even polymer powder based processes cause more challenges than the discussed non-powder polymer processes. Issues such as maintenance, material accountability and sieving and recycling present major challenges to implementers of RM for MC (Table 5). For polymer RM for MC, machine 'openness' regarding modifiability of machine parameters and free choice of material supply and maintenance service presented challenges.

Table 5: Summary of technological AM machine related considerations and challenges

\begin{tabular}{|c|c|c|c|}
\hline Category & Considerations and challenges & $\begin{array}{l}\text { Hearing } \\
\text { Aid }\end{array}$ & Dental \\
\hline \multicolumn{4}{|l|}{ Technical (Machine related) } \\
\hline \multirow[t]{2}{*}{ Pre-installation, installation phase } & - AM machines tend to be adjusted to specific application & $\mathbf{x}$ & $\mathbf{x}$ \\
\hline & $\begin{array}{l}\text { - Raw material had to be developed and process had to be adjusted (material had to } \\
\text { be biocomptible) }\end{array}$ & $\mathrm{x}$ & $x$ \\
\hline Post-commissioning phase & - - & & \\
\hline \multirow[t]{4}{*}{ All implementation phases } & - Maintenance was labour intensive & & $\mathbf{X}$ \\
\hline & - Material accountability was not ideal & & $\mathbf{x}$ \\
\hline & - Sieving and recycling presented a challenge & & $\mathbf{x}$ \\
\hline & $\begin{array}{l}\text { - Machine platform openeness regarding machine parameter modifiability and raw } \\
\text { material and maintenance service choice can be restrictive }\end{array}$ & $x$ & \\
\hline
\end{tabular}

Thus, in the pre-installation and installation phase it is crucial to first narrow down the potential AM process type based on material that is to be used, the required product quality and accuracy, speed of production and flexibility, cost and maintenance aspects (Figure 9). If appropriate machines are available, full working solutions would be preferable as it significantly shortens implementation time (as was observed in Company B by Deradjat and Minshall (2017)). If such solutions are not available, the number of adaptations have to be determined, specifically regarding raw material and the chosen process. A cost benefit analysis should be executed. Another subsequent consideration that has to be taken into account is the above identified degree of machine 'openness'. An open system allows for potential cost savings by cheaper raw material or maintenance services from third parties. However, it is important to note that cheaper material may result in inconsistent material quality. Deriving material from machine suppliers directly often ensures consistent levels of quality, as observed in both metal and polymer RM cases. In some cases, it can be possible to negotiate an open system platform with the AM machine provider if the order volume has a certain size. During all implementation stages, it is crucial that a company implementing metal RM for MC has to account for the fact that some machines have non-ideal material accountability. Powder often has to be manually removed after each run, which requires labour and equipment. 


\section{Technological - Additive manufacturing machine}

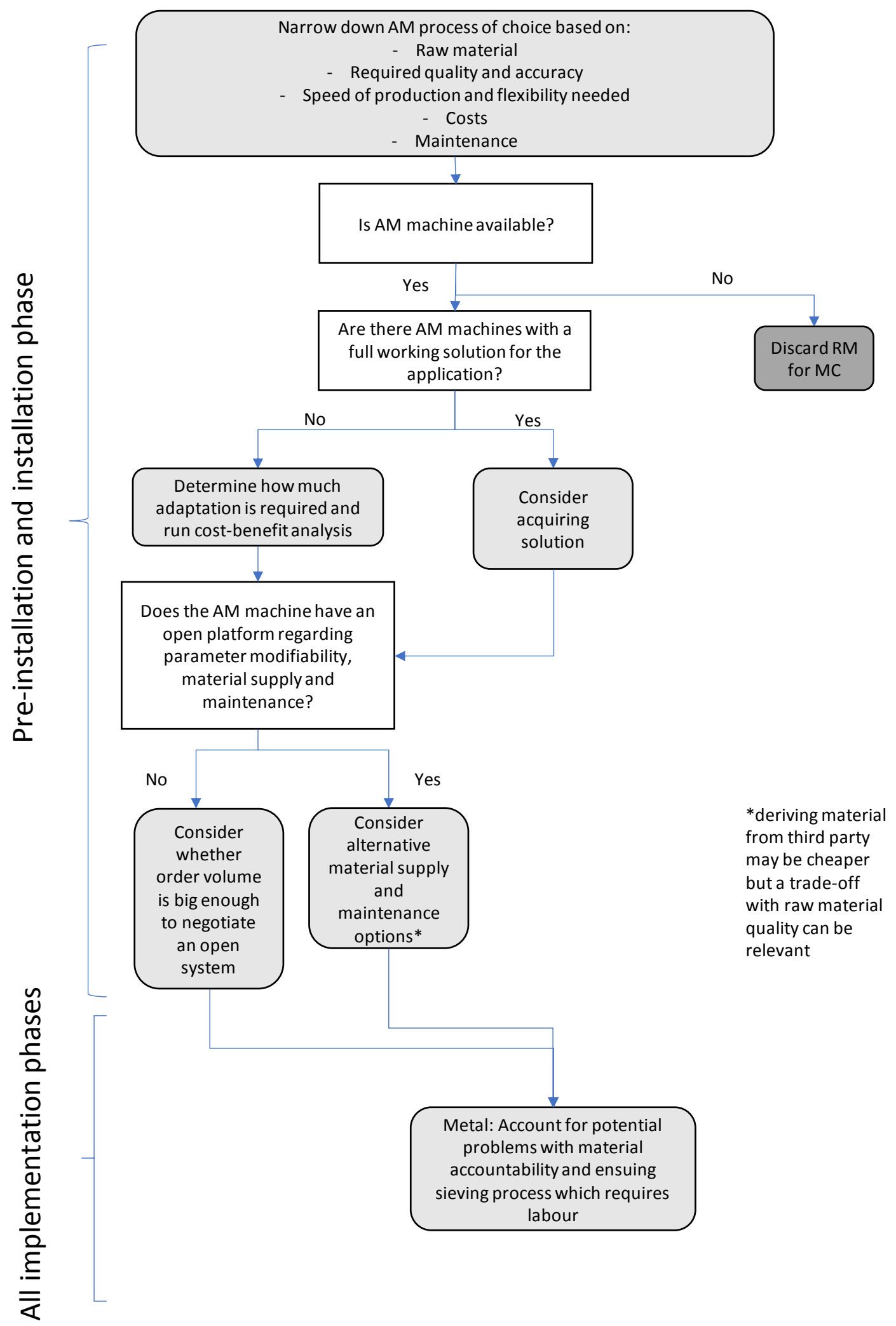

Figure 9: Technological AM-machine considerations. Decision tree for RM for MC implementation 


\subsubsection{Back-end}

Setting up an appropriate post-processing system during the pre-installation and installation phase was one of the most challenging factors that were present in both industries regarding back-end variables (Table 6). Companies have been trying to automate as many post-processing steps as possible but full automation was never attained due to the high level of uniqueness of each product which necessitated manual interaction. A comparison of results between metal RM cases from Deradjat \& Minshall (2017) and the polymer RM cases in this paper have shown that metal AM processes display more challenges in regard to post-processing than polymer based processes, e.g. removal of support structures, annealing processes. Post-processing challenges for polymer processes presented less of a challenge than for metal RM. The hearing aid cases comprised different AM processes and thus displayed different considerations. For the investigated polymer AM processes, SLA and DLP, Companies 1-4 had to account for product handling directly after the AM process because this could present a risk factor due to the fact that the product was in a green state and was subject to deformation. While removal of products after the AM process is more complicated for SLA processes, it required less efforts for DLP processes where a water jet was applied to simply remove support material. These challenges for polymer RM, however, were merely minor and were associated with less resource allocation than back-end factors for metal RM such as mechanical post-processing, support and powder removal.

Table 6: Summary of technological back-end considerations and challenges

\begin{tabular}{|c|c|c|c|}
\hline Category & Considerations and challenges & $\begin{array}{l}\text { Hearing } \\
\text { Aid }\end{array}$ & Dental \\
\hline \multicolumn{4}{|l|}{$\underline{\text { Technical (Back end) }}$} \\
\hline Pre-installation, installation phase & $\begin{array}{l}\text { - Setting up a post-processing system was one of the most challenging actions in the } \\
\text { implementation process }\end{array}$ & $x$ & $x$ \\
\hline Post-commissioning phase & $\cdot-$ & & \\
\hline \multirow[t]{2}{*}{ All implementation phases } & $\begin{array}{l}\text { - Post-processing could not be fully automated due to uniqueness of products (which } \\
\text { require manual interaction) }\end{array}$ & $x$ & $\mathrm{x}$ \\
\hline & $\begin{array}{l}\text { - Removal of support structures could be risky } \\
\text { - Annealing could present a challenge }\end{array}$ & & $\mathrm{x}$ \\
\hline
\end{tabular}

In the pre-installation and installation phase, companies seeking to implement metal RM for MC have to thus establish a product and support removal procedure which requires labour (Figure 10). Secondly, they need to set up a heat treatment step for annealing for some applications. It is important to acquire the appropriate oven and to ascertain the appropriate annealing parameters which vary depending on the batch and product sizes. Lastly, mechanical post-processing requires trained personnel and tools/machinery. As discussed above, during all implementation stages, it is necessary to reduce the risk of employee's damaging parts during the removal and mechanical post-processing step by ensuring appropriate training. For polymer AM processes, the post-processing steps vary depending on the AM process and the products produced. Hence, there will be no further elaboration on the specific postprocessing steps at this stage. In all cases, however, human interaction is always required to at least move objects from one processing station to another. 


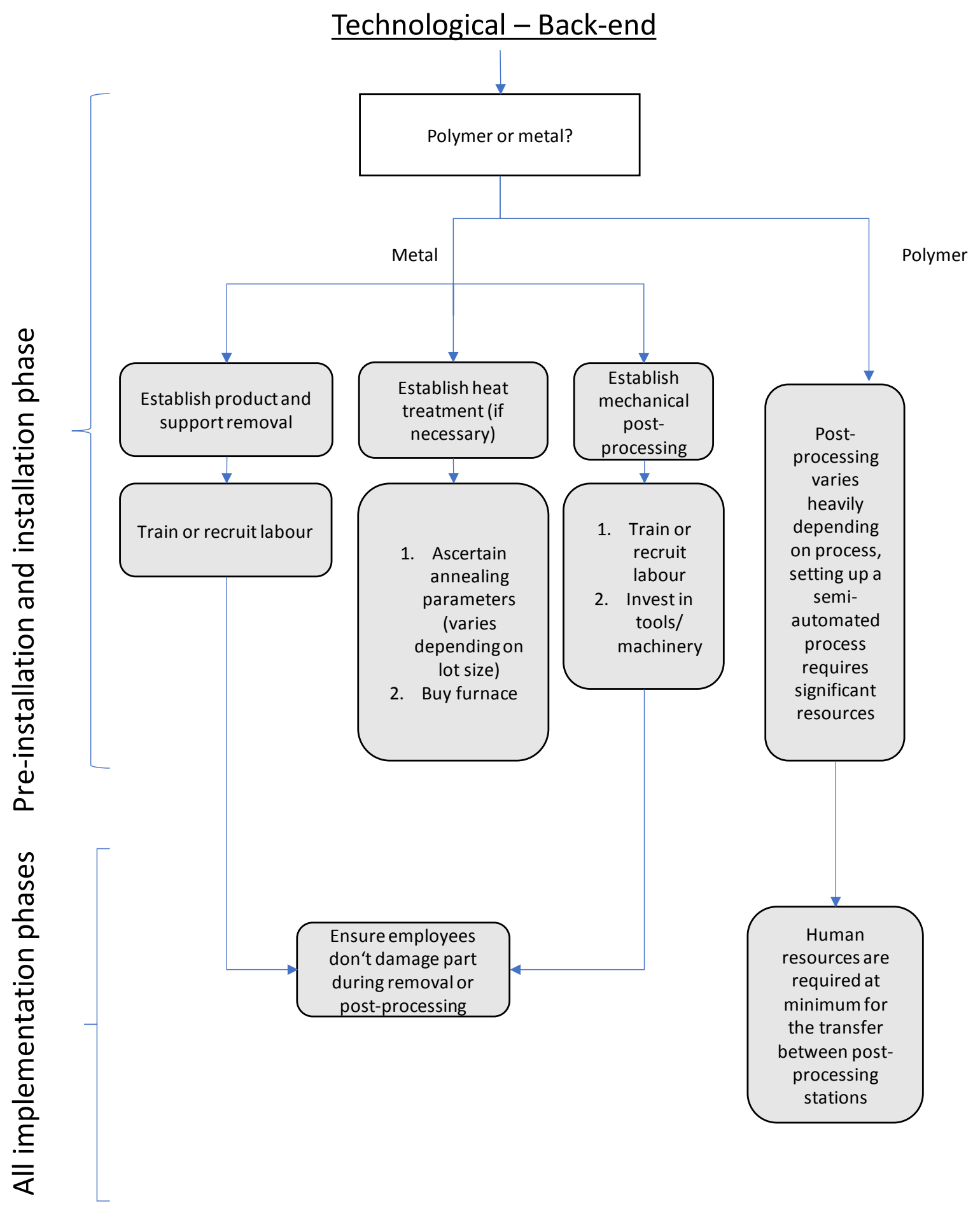

Figure 10: Technological back-end considerations. Decision tree for RM for MC implementation 


\subsection{Operational}

Operationally setting-up a production planning system was a challenge for all companies in both industries during the pre-installation and installation phase (Table 7). Short-delivery times of products during all implementation phases and fluctuating daily demand put strain on production planning throughout all implementation phases. For larger companies, synchronisation of global production presented an additional challenge. Companies in the hearing aid industry, for instance, utilised cheaper labour in China and Ukraine to execute the file design and preparation, which accounted for $50 \%$ of production costs. Production on AM machines was subsequently executed in the US or EU. Additionally, orders could be processed almost immediately, irrespective of the time of the day, because facilities were located in different time zones.

Table 7: Summary of operational considerations and challenges

\begin{tabular}{|c|c|c|c|}
\hline Category & Considerations and challenges & $\begin{array}{l}\text { Hearing } \\
\text { Aid }\end{array}$ & Dental \\
\hline \multicolumn{4}{|l|}{ Operational } \\
\hline Pre-installation, installation phase & $\begin{array}{l}\text { - Setting up a production planning system was considered a challenge and crucial for } \\
\text { the successful implementation of RM for MC }\end{array}$ & $x$ & $\mathrm{x}$ \\
\hline Post-commissioning phase & $\cdot-$ & & \\
\hline \multirow[t]{2}{*}{ All implementation phases } & - Short delivery times put pressure on efficient production planning & $x$ & $x$ \\
\hline & $\begin{array}{l}\text { - Synchronising production planning of production in different plants around the } \\
\text { world has been a challenge (coupled with seasonal and daily fluctuations in } \\
\text { demand) }\end{array}$ & $\mathrm{x}$ & (X) \\
\hline
\end{tabular}

Based on the identified challenges and the contextual insights gained from the cases, the following implementation tree can be derived for operational considerations (Figure 11). Firstly, during the preinstallation and installation phase, it is crucial to determine the type of demand that the enterprise seeking to implement RM for MC is facing: Should there be stable and predictable demand, maximising machine utilisation and delaying production in favour of maximising a production batch is advised. Additionally, if the demand is large enough, utilising an AM machine with a large build platform can increase production efficiency. During all implementation phases, AM production should be executed outside of employee working hours in order to utilise labour more efficiently. If the demand, on the other hand, is fluctuating coupled with short delivery times, AM machines with smaller build platforms tend to be more suitable. Their build platform fills up more quickly and incoming orders can be started much quicker and more frequently. Thus, during the pre-installation and installation phase, it should be determined which machines are to be implemented. During all implementation phases, it can be prudent to allocate a certain slot for urgent orders in each production run or to dedicate a "fast-track production line" in which such orders can be accommodated. If the enterprise is producing at different sites, design and production resources in all sites should be synchronised. Taking advantage of cheaper labour and different time zones in which orders can be processed can be beneficial. 


\section{Operational}

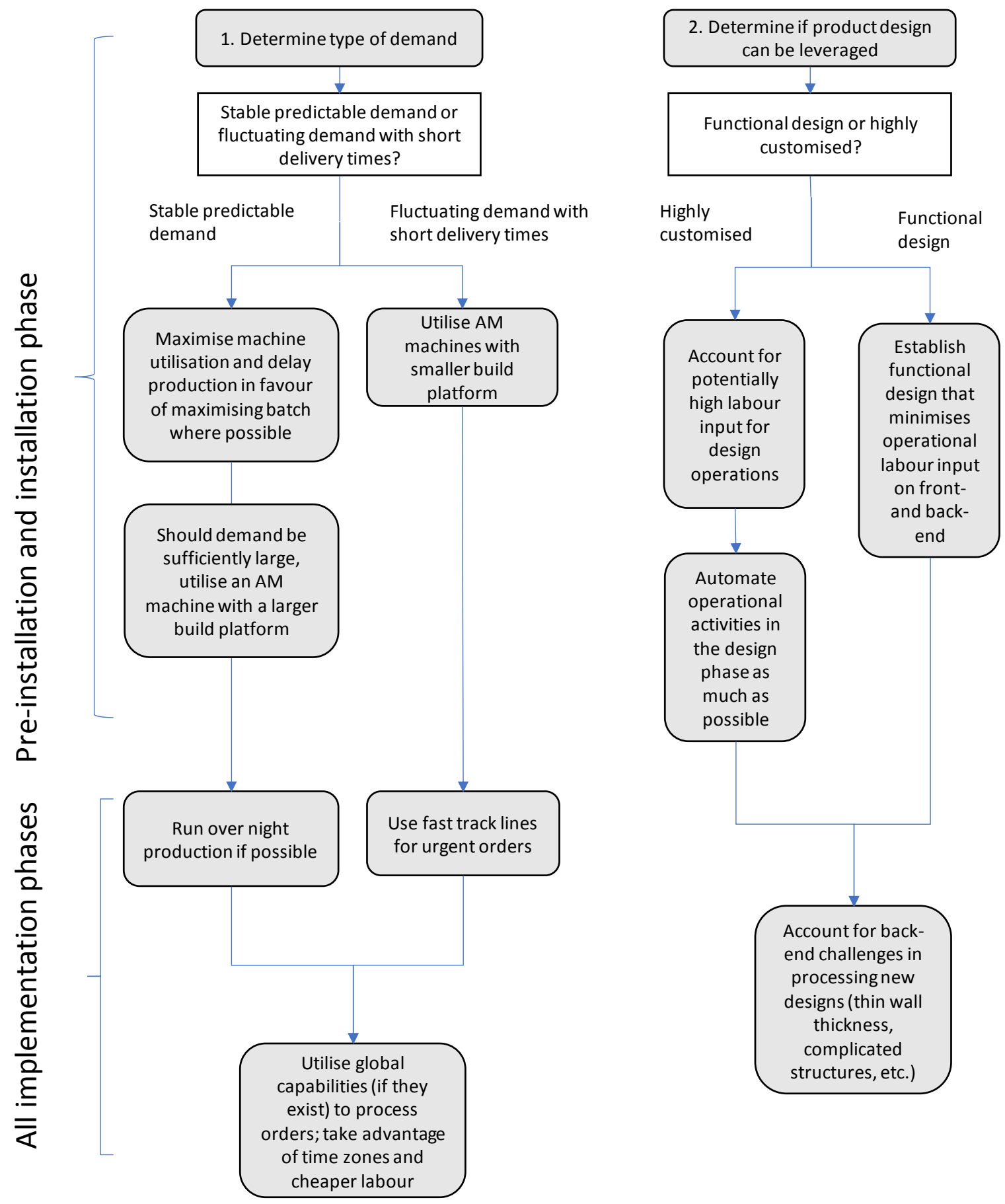

Figure 11: Operational considerations. Decision tree for RM for MC implementation

The second operational consideration that has to be taken into account is the option of whether product design can be leveraged. In the case of a highly customised design, one has to account for potentially 
high labour input for design operations. Thus, operational activities in the design phase should be automated where possible. In the case of functional and complex design, it is important to ensure during the pre-installation and installation phase that the design minimises labour input on front- and back-end. During all implementation phases the new design can potentially cause challenges such as the fact that thin wall thickness can increase the risk of damaging the part in the post-processing.

\subsection{Organisational}

On an organisational level, existing employees had to be retrained or new ones acquired during the preinstallation and installation phase (Table 8). For smaller enterprises in the dental industries, availability of qualified personnel could present a limitation for production ramp-up in the post-commissioning phase. This was less relevant for the hearing aid companies as all of the case companies were large multi-national enterprises. For hearing aid companies, the major challenge was the acquisition of employees involved with the file design and preparation. Production strategies consisted of automation coupled with either maximisation of machine utilisation or prioritisation for production flexibility/speed of production for all case companies in both the hearing aid and dental industry.

Table 8: Summary of organisational considerations and challenges

\begin{tabular}{|c|c|c|c|}
\hline Category & Considerations and challenges & $\begin{array}{l}\text { Hearing } \\
\text { Aid }\end{array}$ & Dental \\
\hline \multicolumn{4}{|l|}{ Organisational } \\
\hline Pre-installation, installation phase & $\begin{array}{l}\text { - Human resources: Retraining and acquiring employees with more technical and CAD } \\
\text { knowledge was a challenge }\end{array}$ & $x$ & $x$ \\
\hline Post-commissioning phase & - Availability of human resources can present a limiting factor for production scale-up & & $\mathbf{x}$ \\
\hline \multirow[t]{2}{*}{ All implementation phases } & - Size of company influenced the implementation of RM for MC & $x$ & X \\
\hline & $\begin{array}{l}\text { - Production strategies consisted of automation coupled with either maximisation of } \\
\text { machine utilisation or prioritisation for production flexbility/speed of production }\end{array}$ & $\mathrm{x}$ & $\mathrm{x}$ \\
\hline
\end{tabular}

Thus, there are three different factors that have to be accommodated when considering organisational aspects involved with the implementation of RM for MC (Figure 12). During the pre-installation and installation phase, implementers need to evaluate their existing human resources and ascertain whether these are sufficient or re-trainable. Should they be re-trainable the cost and time required for retraining should be assessed. Additionally, it is important to note that in later stages of the implementation process, i.e. the post-commissioning phase, it can be a challenge to expand the product portfolio into areas in which the retrained personnel has no knowledge. This was observed for certain dental companies which retrained dental technicians and had difficulties expanding their product lines into nondental applications. If existing staff is not re-trainable, appropriate personnel needs to be recruited or production steps where in-house capabilities are lacking need to be outsourced. 


\section{Organisational}
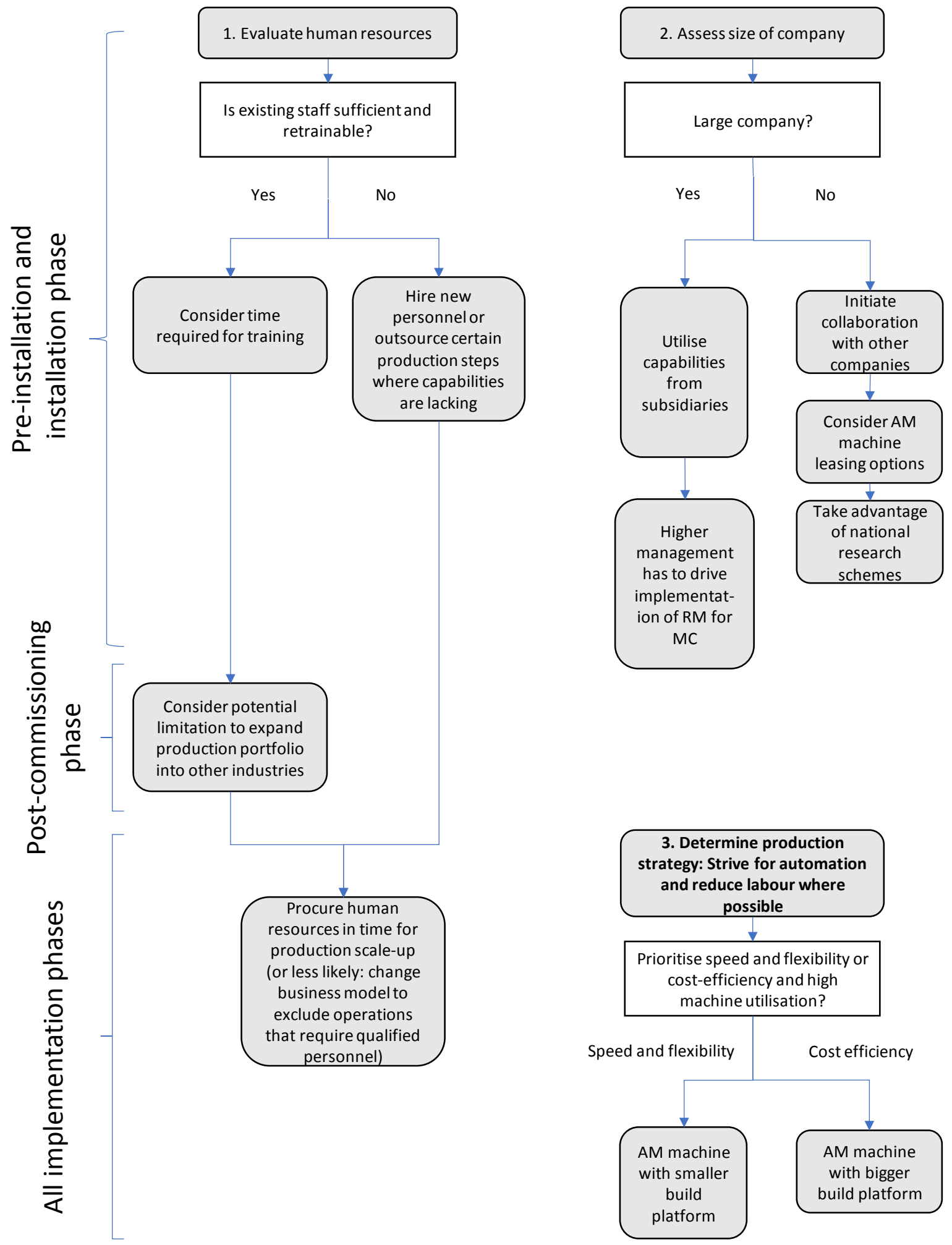

Figure 12: Organisational considerations. Decision tree for RM for MC implementation 
Generally, human resources can be a challenge for production ramp-up in the post-commissioning phase and need to be accounted for. Limiting the scope of complex and time consuming operations such as file generation in the business model can be an alternative solution to address this potential challenge.

Similarly, it is important to be aware of the size and capabilities of a company when implementing RM for MC. Large companies can utilise internal resources and knowledge to execute the implementation. Due to the bureaucratic nature of larger enterprises, it is thus essential to have high level management drive the implementation of RM for MC. As seen in the case companies, especially for companies being pioneers in applying RM in their industry, a strong drive from higher management is essential. For Company 1 , senior management had to proactively support and initiate AM implementation despite initial failures. For smaller companies, collaboration with AM machine producers, software providers, material supplier and/or competitors has to be initiated in the pre-installation and installation phase. Financing options such as leasing and collaborative R\&D supported by national research initiatives can be helpful in the implementation process.

Lastly, it is essential to determine the production strategy that needs to be adopted. All case studies show that striving for automation and reduction of labour was deemed most appropriate for RM for MC. A prioritisation has to be determined, however, for whether a company prefers production speed and flexibility or cost efficiency. In the former case, the enterprise should choose an AM system with smaller build platform so that orders can be executed in shorter intervals as a smaller number of product units are required to warrant a machine run. In the later case, executing a bigger number of orders in a larger machine is financially more beneficial than executing several smaller runs in smaller machines. However, individual orders may take more time to be processed as the waiting time is prolonged until there are enough orders to warrant a production run. The decision as to which approach to adopt depends on the type of demand as illustrated above in the operational section (Figure 11).

\subsection{External}

External considerations comprised the need to collaborate with software providers, AM machine producers and raw material suppliers during the pre-installation and installation phase in order to implement RM for MC (Table 9). Companies in the dental industry, however, relied on collaboration throughout all phases firstly because the majority of companies were smaller than in the hearing aid industry and secondly because there were more product types and materials to research in the dental area. During the early stages of implementing AM products in both industries, customer acceptance of AM products needed to be gained. In both industries, the first companies to implement RM have introduced products of insufficient quality. Thus, they and subsequent implementers of RM had to convince customers of additively produced parts. 
Table 9: Summary of external considerations and challenges

\begin{tabular}{|c|c|c|c|}
\hline Category & Considerations and challenges & $\begin{array}{c}\text { Hearing } \\
\text { Aid }\end{array}$ & Denta \\
\hline \multicolumn{4}{|l|}{ External } \\
\hline \multirow[t]{2}{*}{ Pre-installation, installation phase } & $\begin{array}{l}\text { Collaboration with AM machine producers, software companies and material } \\
\text { suppliers to develop and adjust technical aspects was crucial; the implementation } \\
\text { required the development or extensive adaptations of commercially available } \\
\text { components to the RM system }\end{array}$ & $\mathbf{x}$ & $\mathbf{x}$ \\
\hline & - Customer acceptance of additively produced parts was a challenge in the beginning & $\mathrm{x}$ & $\mathbf{x}$ \\
\hline Post-commissioning phase & $\cdot \quad-$ & & \\
\hline All implementation phases & - Collaboration throughout all phases was relevant for most dental companies & $x$ & \\
\hline
\end{tabular}

Based on the identified challenges and insight from the case studies the following decisions have to be made in regard to external considerations when implementing RM for MC (Figure 13). As a first step during the pre-installation and installation phase, it is crucial to assess whether regulatory requirements can pose a challenge for RM production. High quality standards and regulatory approval of certain products can prevent implementation. Should the regulation be appropriate for implementation, customer acceptance of AM products should be ascertained before production ramp-up. In many cases, as seen in both the hearing aid and the dental cases, resources and time have to be spend to familiarise customers with the quality of AM products if $A M$ has not been applied to the industry before. Conversely, failure of providing convincing product quality can result in additional resources and time required to implement RM for MC as seen in the cases of Company C (Deradjat and Minshall, 2017) and Company 1 . The next step requires establishing collaboration opportunities with different companies such as scanning, software, AM machine, material and maintenance suppliers or competitors. Due to the high level of adaptations that is needed to create a successful RM for MC system collaboration is essential. Unless the company already owns crucial parts required for implementation and unless the risk of exposing sensitive data is perceived as too high, collaboration is unavoidable. In all the 10 case studies, the benefits of collaboration far outweighed the disadvantages. Collaboration often occurs in the pre-installation and installation phase but can also be relevant in the post-commissioning phase to explore new applications and optimisation of production. 


\section{External}

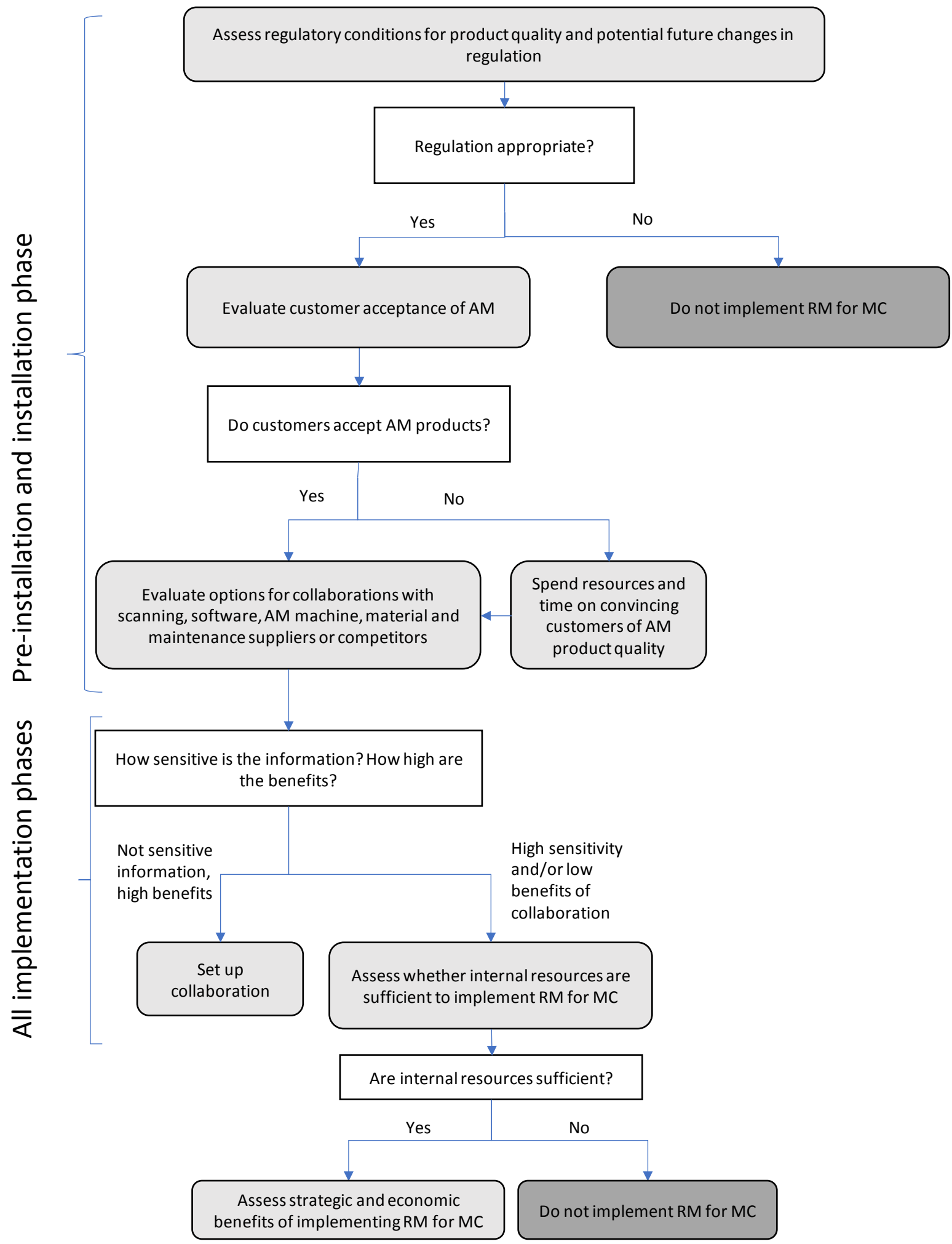

Figure 13: External considerations. Decision tree for RM for MC implementation 


\section{Conclusion and future work}

The paper aims to improve the understanding of which considerations companies have to account for in their decision-making process when seeking to implement RM for MC for the most common AM technologies. Case results from the dental and hearing aid industry have been contrasted and used to develop eight implementation decision trees.

The insights from the case studies show that the framework and list of considerations by Deradjat \& Minshall (2017) are valid for hearing aid applications. Additionally, the influence of implementation stages according to Voss (1988) has been shown for polymer applications. This is illustrated by the identification of varying considerations at different points during the implementation process. The research found 22 common considerations that were for both metal and polymer applications. Four to six aspects for both dental and hearing aids were technology and application specific. These insights directly address the research sub-question of identifying common considerations for metal and polymer RM. Based on these insights and the context of the case studies, eight detailed implementation decision trees for RM for MC were derived. These decision trees represent an expansion of work initiated by Deradjat \& Minshall (2017), Sandström (2015) and Mellor et al. (2014) and directly contribute to addressing the main research question. The findings address a gap in literature on $M C$ enablers in manufacturing as identified by Fogliatto et al. (2012) by providing successful case examples and by increasing the understanding of how to approach the implementation process. The cases from the hearing aid industry illustrate that similar to the dental industry RM enables 'pure customisation' in manufacturing, the highest degree of customisation where every product is unique and specified to the customers' requirements (Lampel and Mintzberg, 1996).

The list of considerations for polymer RM and decision trees provide useful information for management in industry on ascertaining whether RM for $M C$ is appropriate for their business and on how to specifically implement RM for MC. Additionally, it increases understanding of the scope of applicability of $\mathrm{RM}$ and $\mathrm{MC}$ for governmental initiatives which have suggested this approach to strengthen domestic production (DFG, 2017; Innovate UK, 2016; The White House, 2016).

There are limitations to our research that should be noted. The number of case studies limits the generalisability of the research. In addition, general shortcomings inherent with case study based research approaches as described by Yin (2009) are prevalent. The results analysed the implementation of RM for MC only for dental and hearing aid applications. In order to address these shortcomings, future work should include other industry applications and a larger sample size once industry has adopted RM for MC more widely. Additionally, a more evenly spread distribution of SMEs and large sized enterprises in the data set can account for potential implementation differences pertaining to firm size. 


\section{References}

ASTM, 2012. Standard Terminology for Additive Manufacturing Technologies.

Atzeni, E., luliano, L., Minetola, P., Salmi, A., 2010. Redesign and cost estimation of rapid manufactured plastic parts. Rapid Prototyp. J. 16, 308-317.

Bateman, R.J., Cheng, K., 2006. Extending the product portfolio with "devolved manufacturing": methodology and case studies. Int. J. Prod. Res. 44, 3325-3343.

Davis, S., 1987. Future Perfect, Reading. Addison-Wesley.

Deradjat, D., Minshall, T., 2017. Implementation of Rapid Manufacturing for Mass Customisation. J. Manuf. Technol. Manag. 28.

Deradjat, D., Minshall, T., 2015. Implementation of additive manufacturing for mass customisation, in: Pretorius, L. (Ed.), IAMOT 2015-24th International Association for Management of Technology Conference: Technology, Innovation and Management for Sustainable Growth. Cape Town, pp. 2079-2094.

DFG, 2017. Integrative Production Technology for High-Wage Countries [WWW Document]. URL http://www.dfg.de/en/research_funding/programmes/list/projectdetails/index.jsp?id=250 65172 (accessed 2.16.17).

Duray, R., 2011. Process Typology of Mass Customizers, in: Fogliatto, F.S., da Silveira, G.J.C. (Eds.), Mass Customization. Engineering and Managing Global Operations. Springer, London, pp. 29-44.

Duray, R., Ward, P.P.T., Milligan, G.W.G., Berry, W.W.L., 2000. Approaches to mass customization: configurations and empirical validation. J. Oper. Manag. 18, 605-625.

Fogliatto, F.S., da Silveira, G.J.C., Borenstein, D., 2012. The mass customization decade: An updated review of the literature. Int. J. Prod. Econ. 138, 14-25.

Gibson, I., Rosen, D., Stucker, B., 2010. Additive manufacturing technologies. Springer, New York.

Hayes, R.H., Wheelwright, S.C., 1979. Link Manufacturing Process and Product Life Cycles. Harv. Bus. Rev. 57, 133-140.

Herriott, R., Firestone, A., 1983. Multisite qualitative policy research: Optimising description and generalisability. Educ. Res. 12, 14-19.

Holmström, J., Partanen, J., Tuomi, J., Walter, M., 2010. Rapid manufacturing in the spare parts supply chain: Alternative approaches to capacity deployment. J. Manuf. Technol. Manag. 21, 687-697.

Hopkinson, N., Hague, R., Dickens, P., 2006. Introduction to Rapid Manufacturing, in: Hopkinson, N., Hague, R., Dickens, P. (Eds.), Rapid Manufacturing - An Industrial Revolution for the Digital Age. John Wiley \& Sons, Ltd, Chichester, UK, pp. 1-4. 
Innovate UK, 2016. Mapping UK Research and Innovation in Additive Manufacturing. A review of the UK's publicly funded R\&D activities in additive manufacturing between 2012 and 2015. London.

Lampel, J., Mintzberg, H., 1996. Customizing Customization. Sloan Manage. Rev. 38, 21-30.

Lieberman, M.B., Montgomery, D.B., 1988. First-Mover Advantages. Strateg. Manag. J. 9, 41-58.

Mellor, S., 2014. An Implementation Framework for Additive Manufacturing. University of Exeter.

Mellor, S., Hao, L., Zhang, D., 2014. Additive manufacturing : A framework for implementation. Int. J. Prod. Econ. 149, 194-201.

Pham, D.T., Dimov, S.S., 2001. Rapid Manufacturing: The Technologies and applications of Rapid Prototyping and Rapid Tooling. Springer, London.

Piller, F.T., 2008. Observations on the present and future of mass customization. Int. J. Flex. Manuf. Syst. 19, 630-636.

Pine, B., 1993. Mass customization: The new Frontiers in Business Competition, Harvard Business School Press. Harvard Business School Press, Boston.

Reeves, P., Tuck, C., Hague, R., 2011. Additive Manufacturing for Mass Customization, in: Fogliatto, F.S., da Silveira, G.J.C. (Eds.), Mass Customization. Engineering and Managing Global Operations. Springer, London, pp. 275-289.

Ruffo, M., Tuck, C., Hague, R., 2007. Make or buy analysis for rapid manufacturing. Rapid Prototyp. J. 13, 23-29.

Sandström, C.G., 2015. The non-disruptive emergence of an ecosystem for 3D Printing Insights from the hearing aid industry's transition 1989-2008. Technol. Forecast. Soc. Change 102, 160-168.

Silveira, G. Da, Borenstein, D., Fogliatto, H.S., 2001. Mass customization : Literature review and research directions. Int. J. Prod. Econ. 72, 1-13.

The White House, 2016. Revitalizing American Manufacturing. Washington, D.C.

Tuck, C., Hague, R., Ruffo, M., Ransley, M., Adams, P., 2008. Rapid manufacturing facilitated customization. Int. J. Comput. Integr. Manuf. 21, 245-258.

Voss, C., 1988. Implementation: A key issue in manufacturing technology: The need for a field of study. Res. Policy 17, 55-63.

Weller, C., Kleer, R., Piller, F.T., 2015. Economic implications of 3D printing: Market structure models in light of additive manufacturing revisited. Int. J. Prod. Econ. 164, 43-56.

Westbrook, R., Williamson, P., 1993. Mass customization: Japan's new frontier. Eur. Manag. J. $11,38-45$.

Wohlers, T., Caffrey, T., 2016. Wohler Report 2016. Fort Collins. 
Wong, K. V., Hernandez, A., 2012. A Review of Additive Manufacturing. ISRN Mech. Eng. 2012, $1-10$.

Yin, R., 2009. Case Study Research. Design and Methods, 4th ed. SAGE Publications, London. 